Para enlazar con este artículo / To link to this article:

http://dx.doi.org/10.6035/MonTI.2021.13.02

Para citar este artículo / To cite this article:

Jiménez-Crespo, Miguel Ángel \& Maribel Tercedor Sánchez. (2021) "Explicitation and implicitation in translation: Combining comparable and parallel corpus methodologies." In: Calzada, María \& Sara Laviosa (eds.) 2021. Reflexión crítica en los estudios de traducción basados en corpus / CTS spring-cleaning: A critical reflection. MonTI 13, pp. 62-92.

\title{
EXPLICITATION AND IMPLICITATION IN TRANSLATION: COMBINING COMPARABLE AND PARALLEL CORPUS METHODOLOGIES
}

\author{
Miguel ÁNGEL JiMÉNEZ-CRESPO \\ jimenez.miguel@rutgers.edu \\ Rutgers University \\ MARIBEL TERCEDOR SÁNCHEZ \\ itercedo@ugr.es \\ Universidad de Granada
}

\begin{abstract}
This paper studies explicitation and implicitation in translated medical texts using a combination of comparable and parallel corpus methodologies. Previous corpus research in this domain has shown common lexical and syntactic shifts between translated and non-translated texts (Askehave \& Zethsen 2000; Jensen \& Zethsen 2012), including differences in explicitation rates surrounding Latin-Greek (LG) terms (Jiménez-Crespo \& Tercedor 2017). A parallel corpus section was compiled in order to identify whether the observed higher explicitation ratios in English to Spanish translations when compared to similar non-translated texts in this last study are due to (1) cross-linguistic interference or replication of source text structures, or (2) to the translational tendency to explicitate. The results point to a possible combination of both, with $21 \%$ of cases of explicitation and no implicitation. Higher explicitation ratios mainly support the interference or cross-linguistic influence hypothesis (Kruger 2018). This study also offers support for the risk aversion hypothesis (Pym 2005, 2015; Kruger 2018; De Sutter \& Kruger 2018), as translations only show a tendency to include clearer and more explicit formulations.
\end{abstract}


Keywords: Explicitation; Implicitation; Medical Translation; Medical Terminology; Parallel and Comparable Corpus Studies.

\section{Resumen}

En este artículo se estudian las estrategias de explicitación e implicitación en textos médicos traducidos del inglés al español mediante el análisis de un corpus comparable y otro paralelo. Estudios de corpus previos han mostrado que existen diferencias léxicas y sintácticas en los textos traducidos al compararlos con los no traducidos (Askehave \& Zethsen 2000; Jensen \& Zethsen 2012), entre ellas diferencias en los porcentajes de explicitación de términos médicos de origen grecolatino (Jiménez-Crespo \& Tercedor 2017). Se compiló un corpus paralelo con el fin de analizar si el mayor porcentaje de explicitación observado en las traducciones ingles-español con respecto a textos no traducidos en este último estudio se debe (1) a interferencia interlingüística o calcos de estructuras textuales de la lengua origen, o (2) a la tendencia a explicitar, propia de la traducción. Los resultados apuntan a una posible combinación de ambas. La tendencia a explicitar apareció en $21 \%$ de posibles casos, sin ningún caso de implicitación. Estos resultados confirman mayoritariamente la hipótesis de interferencia o influencia interlingüística (Kruger 2018). Además, respaldan la hipótesis de la aversión al riesgo (Pym 2005, 2015; Kruger 2018; De Sutter $\&$ Kruger 2018), pues las traducciones solo muestran una tendencia a la inclusión de formulaciones más claras y explícitas.

Palabras clave: Explicitación; Implicitación; Traducción médica; Terminología médica; Estudios de corpus paralelos y comparables.

\section{Introduction}

Explicitation is the general feature, tendency, or universal of translation that has sparked the highest interest in the scholarly community, including the largest body of theoretical research (e.g. Pym 2005; Becher 2011; HansenSchirra et al. 2007; Murtisari 2013, 2016; Kruger 2014; De Metsenaere \& Vandepitte 2017). The present study was motivated by a previous comparable corpus study on explicitation (Jiménez-Crespo \& Tercedor 2017). This study showed that medical translations from English into Spanish contained significantly higher lexical explicitation ratios for Latin and Greek terms (LG terms) (e.g. hypoglycemia or high blood sugar, dyspnea or difficulty breathing) than similar non-translated texts. 
For the purposes of the present study, a parallel section was added to the existing comparable corpus. A comparable corpus can be defined as "a structured electronic collection of texts originally written in a particular language, alongside texts translated into that same language" (Baker 1995: 234), while a parallel corpus is a collection of texts alongside their translation(s) (Laviosa 2002: 37). The addition of the parallel section allows for the comparison of source and target texts, and this was used to test whether these higher ratios of explicitation were due to: (1) the mere replication of source text structures, indicative of language, text type and genre-specific differences in lexical use between the language pair in question; (2) the translation process, as a specific type of communicative event (Baker 1995), resulting in explicitation shifts; or (3) a combination of both. The corpus and the compilation process will be described in detail in the methodology section.

From a theoretical and methodological perspective, the motivations of the study are twofold. On the one hand, the existing debate on whether comparable corpora by themselves are an ideal methodology to study explicitation (Hansen-Schirra et al 2007; Murtisari 2016; De Maurentis \& Vandepitte 2017). Researchers have argued that this methodology limits the formulation and testing of hypothesis on the causes of explicitation, as source texts are not included (e. g. Kruger 2014: 167, 2018: 23, 25). On the other, it is also motivated by the need to combine the study of explicitation/ explicitness with implicitation / implicitness (Becher 2010; Kathelijne 2012; Kruger 2014; Van Beveren, De Sutter \& Colleman 2018). Normally, as indicated a decade ago (Klaudy \& Karoly (2005: 14), the number of results revealing explicitation have greatly outnumbered those of implicitation, and this was the foundation of the asymmetry hypothesis. This hypothesis states that, in any given language pair, explicitation and implicitation cannot be considered as symmetric tendencies. In this regard, it is common that "obligatory, optional and pragmatic explicitations tend to be more frequent than the corresponding implicitations regardless of the SL/TL constellation at hand." (Becher 2010: 17).

Following the programmatic direction by several scholars such as Becher (2011) and Klaudy (2004), different studies have explored explicitation and implicitation jointly. Most of them have shown that translators normally 
prefer explicitation rather than implicitation strategies in different types of domains, such as legal texts (Hjort-Pedersen \& Faber 2010; Faber \& Hjort-Pedersen 2013), scientific texts (Kruger 2015), children's literature (Erfieni 2017); back translation (Makkos \& Robin 2014), contrasting expert and students' literary translations (Maraeva 2017), and different language specific features in language combinations such as Russian-English (Tao \& Jiang 2017). Nevertheless, in a very small number of studies contradictory evidence has also been found (Van Beveren, De Sutter \& Colleman 2018).

The textual genre and translation type selected for the study are not casual. The corpus consists of original and translated medical websites with information about health issues for the general public. This type of expert to layperson genre represents an ideal context to study explicitation and implicitation phenomena, because lexical and syntactic usage has to be adjusted to the expectations of end users and to genre conventions. This is so in both intralingual translation through so-called intralinguistic explicitation (HillMadsen 2015) taking place in expert to non-expert communication, as seen in the composition of source texts themselves, as well as in explicitation/ implicitation shifts resulting from the translation process.

The specific case of English to Spanish directionality also offers an ideal context to study lexical explicitation-implicitation. Both languages display different lexical variation strategies and patterns of use of medical concepts (e.g. Alarcón, López \& Tercedor 2016). Latin and Greek (LG) terms are more widely used in Spanish than in English. Therefore, a medical LG term might be adequate in a Spanish text addressed at the non-expert, but this same term would only be found in a more specialized expert-to-expert text in English (Campos Andrés 2013). Support for this fact is also found in the comparable corpus study by Jiménez-Crespo \& Tercedor (2017), where the rate of use of LG terms was far less frequent in translations according to normalized frequency lists. These differences were found to be statistically significant. It was also found that even when LG terms were less frequently used in translations, they also showed higher reformulation/explicitation ratios. This means that translators might simply replicate patterns of lexical use in source texts, including cases of intralinguistic explicitation, that is, LG terms with the lay terminological variant (e.g. myalgia, also known as pain in the muscles; myalgia or muscle pain). In addition, Campos Andrés (2013: 
53) indicates the translation of medical patient guides from English into Spanish does not always require to directly transfer intralinguistic explicitation formulations (e.g. dyspnea or difficulty breathing) or doublets (e.g. scaring or cicatrization) in source English texts: these LG terms can be perfectly understood by Spanish lay audiences. Again, the previous study offers support for this recommendation, as LG terms showed markedly higher frequency in non-translated texts than in translated ones (Jiménez-Crespo $\&$ Tercedor 2017). Oftentimes, the Spanish target reader has a higher chance of being familiar and acquainted with terms of LG origin than the English language reader, since they are common in general language. An example can be otorrinolaringólogo: this LG term is commonly used in Spanish while English commonly uses ENT or Ear-Nose-Throat doctor.

The present paper is structured as follows. It first briefly reviews the notions of explicitation and implicitation in Translation Studies, as well as the different hypotheses proposed and recent empirical studies about their causation. It then reviews explicitation and implicitation in translated medical texts, with a focus on the English-Spanish combination. It presents the actual phenomena under study, determinologization and the strategies used to adjust the degree of terminological specialization that involve explicitation/implicitation shifts, as well as shifts in the degree of technicality or specialization of texts. This is followed by an overview of the working hypotheses, the methodology used and the types of variables and shifts identified. The results obtained are then presented with a discussion.

\section{Explicitation and implicitation in Translation Studies}

Explicitation can be considered as the most popular and widely studied "universal of translation" (Baker 1995), "general feature of translation" (Chesterman 2004), or "general tendency in translation" (Olohan 2004) in the subdiscipline of Corpus-Based Translation Studies (CBTS) (Laviosa 2002). The origins of this research trend can be traced to the seminal studies of Blum-Kulka (1986), Klaudy (1989), Øverås (1998) or Olohan \& Baker (2000). Explicitation was initially defined by Vinay \& Darbelnet ([1958] 1995: 342), as a "stylistic translation technique that consists of making explicit in the target language what remains implicit in the source language 
because it is apparent from either the context or the situation". Another seminal definition in TS is that by Baker, who defines explicitation as "an overall tendency to spell things out rather than leave them implicit" (Baker 1996: 180). Blum-Kulka, on her part, defined her explicitation hypothesis as an "observed cohesive explicitness from SL to TS texts regardless of the increase traceable difference between the two linguistic and textual systems involved" (2001: 30). More recent definitions indicate that explicitation "is observed where a given target text is more explicit than the corresponding source text" (Becher 2011: 19). Explicitation emerges in all instances of language mediation (Blum-Kulka 1986:19), including intralinguistic and interlinguistic communicative processes (Hill-Madsen 2015). Theoretical studies on explicitation often refer back to the Klaudy's $(1988,2009)$ seminal distinction between obligatory, optional, pragmatic explicitation and translation-inherent explicitation, the last type being highly controversial (e.g. Becher 2011). Obligatory explicitation is "dictated by the differences in the syntactic and semantic structures of languages" (Klaudy 2009: 106), while optional explicitation is motivated by differences between the source and target language systems. That is the case of the studies on optional explicitation of the complementizer that in English or om in Dutch (Olohan \& Baker 2002; Kruger 2018; Beveren De Sutter \& Colleman 2018). These particles are compulsory in some languages but optional in others. Other studies have explored, for example, the omission of the subject personal pronoun in Spanish when translating from English (Jiménez-Crespo 2012), showing higher rates of explicitation of the subject pronoun, even though Spanish is a pro-drop language. Pragmatic explicitation is motivated by differences in the cultural or world knowledge of the source and target text audiences. The last type, translation-inherent explicitation, is the most controversial. It is caused by "the nature of the translation process itself" (Klaudy 2008: 107). This type has been the object of several studies that have attempted to dismiss it as harder to identify or justify (e.g. Becher 2011). De Metsenaere $\&$ Vandepitte (2017), for example, argue that the notion of translation inherent explicitation should be eliminated and all instances under what they call language systematic categories, or simply in the pragmatic category, as explicitation is seen as a strategy to avoid risk in communicative settings. Becher (2011), on his part, indicates that this category is not clearly defined 
by Klaudy, and this is exemplified by the fact that this is the category in which Klaudy herself fails to provide any guiding examples in her work, thus proving that this is a fuzzy and unclear category.

On its part, the opposite tendency, implicitation, has relatively been neglected in TS until the last decade (Kruger 2014: 164). Vinay \& Darbelnet defined it as "making what is explicit in the source language implicit in the target language, relying on the context or the situation for conveying the meaning" (Vinay \& Darbelnet 1995: 344). Similarly, Becher indicates that implicitation "is observed where a given target text is less explicit (more implicit) than the corresponding source text" (2010: 51). The study of implicitation has regularly been approached as a factor or condition influencing explicitation.

This brief summary of definitions is by no means comprehensive, and many other works offer intense debate on definitions and approaches to explicitation and implicitation (Pym 2005; Becher 2010; Murtisari 2016; De Metsenaere $\&$ Vandepitte 2017). This heterogeneity of approaches and epistemological fuzziness has complicated a unified approach that allows for comparison of studies across the board. Often, studies are based on different theoretical frameworks and points of departure, such as the latest studies that attempt to define explicitation based on the notions of explicitness from Relevance Theory (e.g. Murtisari 2016; De Metsenaere \& Vandepitte 2017). According to De Metsenaere \& Vandepitte (2017: 383), approaches have been:

[of] very heterogeneous nature, which has made it difficult, if not impossible to compare their findings and to come to conclusive insights into the meanings of explicitation and implicitation in and for translation and translation studies.

The issues surrounding explicitation and implicitation are also complicated by the fact that tendencies are often "tentatively proposed on the basis of empirical results pertaining only to a subset" (Chesterman 2004: 40), that is, limited to a phenomenon observed in a specific corpus or language combination. Similarly, scholars have proposed to incorporate in the study of explicitation multiple variables, such as genre, register, and level of specialization. For example, in a study by Kruger (2016) the degree of technicality or level of specialization of a text was found to correlate to higher explicitation ratios. He found that in an expert-to-expert subcorpus of technical texts there was 
a higher rate of explicitation than in an expert-to-semi-expert subcorpus exhibiting a medium degree of technicality.

Nevertheless, without any doubt, the "tendency" to explicitate has been mostly confirmed in most textual subsets or translation contexts in CBTS research, including different language combinations, textual genres, different levels of language, and in a number of translation modalities, such as subtitling (Perego 2003) or localization (Jiménez-Crespo 2011, 2016). It has also been confirmed on different translational phenomena, such as translated texts vs. edited-revised translations (Kruger 2012; Bisiada 2017) or even consecutive (Tang 2018) or simultaneous interpreting (Ewa 2006). However, some studies have also found inconclusive evidence or are cautious about attributing the identified effects to explicitation, such as Puurtinen (2004), Englund Dimitrova (2005), Cheong (2006) or Hansen-Schirra et al. (2007).

Recent studies have not only tried to ascertain whether the explicitation hypothesis is empirically confirmed, but have also tackled issues of causation and procedures for testing it, primarily since the advent of advanced multifactorial statistical analysis in Translation Studies (e.g. Oakes and Ji 2012; Kruger \& De Sutter 2018; De Sutter \& Lefer 2020). In this sense, CBTS has progressed towards a more theoretically robust and methodologically sound treatment of these phenomena (e.g. Becher 2010; Kruger 2013, 2018; Halverson 2016; De Sutter et al. 2018). Studies have tested the different proposed hypotheses, more specifically the source-language transfer hypothesis (Becher 2010), also known as the interference or cross-linguistic influence (CLI) effects (Kruger \& Van Rooy 2016; Kruger 2018), the risk-aversion hypothesis (Pym 2005, 2015) and the processing-strain hypothesis (Olohan $\&$ Baker 2000). According to the cross-linguistic influence effects hypothesis, features or tendencies in translated texts can possibly be traced back to the replication of source language structures when contrastive differences between source and target systems exist (Kruger \& Van Rooy 2016; Kruger 2018). Therefore, under certain conditions, source language preferences might be transferred to translations. In the case of explicitation, a source text in a language "with a preference for greater explicitness" might result "in a target text that demonstrates increased explicitness in comparison with non-translated texts in the same language" (Kruger 2018:7). This could be the cause behind the higher explicitation ratios observed in the previous 
study (Jiménez-Crespo \& Tercedor 2017). If English has a preference for greater lexical explicitness when using LG terms than Spanish, the higher ratios observed in the comparable corpus study would be simply caused by this effect. The risk aversion hypothesis, according to Pym (2005) assumes that, in any translation process, taking a 'risk' might be associated to a partial or complete failure in communication, the main purpose of translation. Therefore, translators, in a receiver-oriented view of communication, make information more easily available to the target audience. This includes the possibility of explicitation, in order to reduce the potential risk of lack of understanding. According to the processing strain hypothesis / cognitive complexity hypothesis (Beveren, De Sutter \& Colleman 2018; De Kruger $\&$ De Sutter 2018), translators might select the most frequent option in translation to reduce effort. In this case, if the implicit form might be the most frequent option, translators might select it to reduce cognitive load, regardless of other factors.

Recent studies into the causation of explicitation have dismissed the cross-linguistic influence hypothesis (Kruger \& De Sutter 2018), and they have offered some support for the processing strain hypothesis / cognitive complexity hypothesis (Beveren, De Sutter \& Colleman 2018). Nevertheless, a majority of studies conclude that the risk-aversion hypothesis is the most probable cause of explicitation (Becher 2010; Kruger 2018; Kruger \& Van Rooy 2016; Kruger \& De Sutter 2018; Kruger 2018), even when risk aversion might not always imply explicitation (Kruger $\&$ De Sutter 2018).

\section{Explicitation/ Implicitation in the translation of medical texts}

According to Montalt, Zethsen \& Karwacka (2018: 29), “[a]ppropriate use of medical terminology is one of the core conditions for successful communication in monolingual and multilingual healthcare communities". Nevertheless, one of the main issues that translators face is "adapting their terminological choices to genre-specific and register-specific conventions" (Montalt, Zethsen $\&$ Karwacka 2018: 30). In this problem area, medical LG terms play a key role because, even when they are commonplace in all languages, their coexistence with vernacular terminological variants varies from language to language (Askehave \& Zethsen 2000; Zethsen 2004; Gutiérrez 
Rodilla 2014; (Jiménez-Crespo \& Tercedor 2017). Latin was not incorporated to the same extent in all European Languages (Zethsen 2004: 132), and while Spanish, Italian and French medical terminology is eminently Latin and Greek in origin, Northern European languages possess a double-layer medical terminology. In these languages, many scientific LG words find lay or lower register counterparts (e.g. clotting / coagulation, scar / cicatrization), while in Romance languages only the Latin based ones exist ('coagulación' and 'cicatriz' respectively). Therefore, what "in Latin-based languages might sound too low a register is perfectly acceptable as scientific terminology in English" (Montalt-Resurrecció \& González Davies 2007: 242). This can result in different issues, because due to historical differences "seemingly identical words may indeed be false friends in an interlinguistic context" and they might also present issues related to the "connotative differences, e.g. at the level of formality" (Zethsen 2004: 131-132). For example, one of the most common ways in which synonymy occurs in medical and scientific domains in English is through the existence of the technical term with its more or less specialized equivalents or doublets, such as with "cephalalgia" and "headache". It is often understood that these cases of synonymy are "a source of translation problems because languages are not symmetrical in their use: for example, what in Spanish is considered to be low register may be perfectly acceptable in English in the same text genre" (Montalt 2011: 80).

Explicitation is part of an intralinguistic communicative process known as reformulation or determinologization. This is one of the most frequent strategies at the lexical level to lower the register and adapt textual genres to non-expert readership. This process appears in medical texts both in intralingual translation such as the case of research articles summarized for lay audiences in the Annals of Internal Medicine (Muñoz-Miquel 2012: 200-202), or also in translated texts for general audiences (Tercedor \& López Rodríguez 2012). This process involves using general language to communicate the meaning of a specialized term (Meyer $\&$ Mackintosh 2000), helping to close the gap between specialized knowledge and lay audiences. Montalt and Shuttleworth (2012: 16) refer to determinologization as:

a process of recontextualisation and reformulation of specialized terms aiming at making the concepts they designate relevant to and understandable by a lay audience. This process is motivated by specific cognitive, social 
and communicative needs, and takes place as part of a broader process of recontextualisation and reformulation of discourse.

This process involves a large number of potential strategies that are covered under this hypernym such as explanation, definition, reformulation, exemplification, illustration, analogy, comparison and substitution by a more popular term (Campos Andrés 2013; Montalt \& González Davies 2007: 252253). According to Montalt and González Davies (2007), this process can involve a number of strategies to deal with LG terms:

(1) Retain LG term adding an explanation: Poliuria, increase in the volume of urine.

(2) Retain LG term in parenthesis after the explanations: increase in the volume of urine (poliuria).

(3) Retain LG after a popular term: bad breath or halitosis.

(4) LG term is omitted and replaced by explanations or popular terms: patients can experience an increase in the volume of urine.

All these mechanisms can help increase the readability and efficiency of translated medical texts for lay readers, but also relate to explicitation. If reformulation or determinologization represents a natural mechanism in intralingual translation in medical genres, the translation process can potentially increase or decrease the frequency and nature of the explicitation strategies naturally present in these texts. The study of explicitation in translated medical texts therefore has to take into consideration the compounding effect of reformulation as an intralinguistic and intergeneric translation strategy (Ezpeleta 2012), as well as the potential general explicitation tendency in translated texts.

\section{Empirical study}

The present study focuses on lexical explicitation. Some studies have focused on semantic explicitation such as Puurtinen (2004), who zooms in connectives to identify the type of semantic relation that is conveyed. Øverås (1998:5) includes in her study both grammatical and lexical explicitation, but the former has primarily been the objective of a handful of studies on 
translations of literary texts (e.g. Olohan $\&$ Baker 2000). The research questions for this study are the following:

1. Research question 1 (RQ1): Do findings from parallel corpora support the explicitation tendency already observed in translated texts through a comparable corpus methodology? This would be expected as previous literature shows that explicitation shifts tend to outnumber implicitation ones, even when implicitation might be appropriate for the English to Spanish combination in medical translation.

2. Research question 2 (RQ2): If higher explicitation ratios are found, do they offer support for the proposed cross-linguistic effect hypothesis and-or the risk aversion hypothesis? ${ }^{1}$ This will depend on whether higher explicitation rates are due solely to the replication of source text structures in translation in combination with text type and genre specific differences between the languages under study (EN, ES), or whether translators also make use of explicitation strategies during the translation process.

The hypotheses for the study are:

(1) Hypothesis 1 (H1). Translated texts will show higher ratios of explicitation than implicitation.

(2) Hypothesis 2 (H2). Explicitation in translated texts will mostly be due to a combination of ST structure replication, as well as to translation-inherent explicitation.

\subsection{Methodology: The parallel and comparable corpus}

This study applies a parallel and comparable corpus methodology, the preferred methodological option to research explicitation and implicitation (Hansen-Schirra et al. 2007; Murtisari 2016). The Translational Web Corpus of Medical Spanish (TWCoMS) (Jiménez-Crespo 2014; Jiménez-Crespo \& Tercedor 2017) was used, a comparable corpus project conceived as a tool to study variation in translated medical terminology in the United States applied to the VariMed project terminological database (http://varimed.

1. The processing-strain hypothesis (Olohan \& Baker 2001) has been discarded for this study. Previous studies have tested it using complexity -related factors related to syntax (Beveren, De Sutter \& Colleman 2018) and this study focuses primarily on a noun-phrases related to explicitation of LG terms. 
ugr.es) (Tercedor, López Rodríguez \& Prieto Velasco 2014). It includes a section of non-translated medical websites addressed at lay readers in Spanish alongside a representative sample of Spanish translations of US medical websites. For the purposes of the present study, a small parallel subcorpus was also added to the TWCoMS, consisting of the largest English websites and their Spanish versions (CDC.gov, MedlinePlus, Womenshealth.gov, Cancer. gov). The comparable portion of the corpus was downloaded and compiled in 2014, and the parallel section in late 2018. The comparable section of the TWCoMS corpus contains medical websites addressed at general audiences in the US and a comparable section of websites localized for Latin America, Mexico and Spain markets.. The translational subcorpus contains 32,330,052 tokens. The comparable non-translational section contains 8,701,867 tokens.

The parallel section was compiled using the Httrack software. Research has shown that localized websites are normally smaller than the original counterparts (Jiménez-Crespo 2012), and therefore, not all source webpages in English in the websites compiled had a Spanish version. For example, once the website for the Center for Disease Control was downloaded there were over 244,000 pages, but only 2,540 were in Spanish. In addition, only 1,834 were direct translations with a corresponding source webpage. The overall parallel corpus thus includes 16,534 source pages with their corresponding localized web pages from the websites Center for Disease Control (CDC.gov), Cancer.gov, WomensHealth.gov and Medlineplus.gov. The corpus was aligned at the page level, and not at the segment level. Since Httrack allows us to download the websites with their internal structures, and each Spanish page has an "English" translation link and vice versa, the searches were carried out in the html version of the corpus by means of identifying the terms used and looking at the localized counterpart.

The terms under study are the original terms used in previous studies (Jiménez-Crespo 2017; Jiménez-Crespo \& Tercedor 2017). These terms were originally selected at random with the Excel function from the VariMed terminological variation website from an initial list of 100 concepts:

(1) Dysmenorhea - 'dismenorrea' : painful periods

(2) Dyspnoea - 'disnea' : difficulty breathing

(3) Halitosis - 'halitosis' : bad breath 
(4) Hematuria - 'hematuria' : presence of blood in the urine

(5) Hypoglycemia - 'hipoglucemia' : low blood sugar

(6) Hysterectomy - 'histerectomía' : surgical removal of the uterus

(7) Myalgia - 'mialgia' : muscle pain

(8) Polydipsia - 'polidipsia' : excessive thirst

(9) Polyuria - 'poliuria' : excessive volume of urine

(10) Rhinorrhea - 'rinorrea' : nasal dripping

(11) Tachypnea - 'taquipnea' : fast breathing

(12) Xerosis - 'xerosis' : dry skin

(13) Xerostomy - 'xerostomía' : dry mouth

All instances of use of these terms in both the source and target texts were recorded in a database. Only segments using the LG terminological variant in one or both languages were annotated. This means it is possible that cases with two or more lay terms that could also involve explicitation- implicitation shifts were not recorded. Nevertheless, due to the lack of lexicalization of some these lexical units (e.g. hypoglycemia = low blood sugar, low sugar in the blood, abnormally low level of sugar in the blood, etc.), as well as the wide range of possible lay term variants for the different concepts under study, it was decided to focus on LG terms only. The record in the database included both source and target segments, as well as any possible translation shifts (see next section). The two types of recorded phenomena were implicitation - explicitation shifts and shifts in the degree of specialization (see next section). The analyses started from a search in Spanish for the probing medical terms, and once the page opened, the English source webpage was analyzed. In a second search, the direction was the inverse in order to identify LG terms in the source texts that might not have been translated into a LG term in Spanish. The translation pair recorded was the first appearance of the LG term per webpage. There is usually a repetition of the same translation solution for a single concept in a webpage, and therefore only the first instance in the running text when the concept is first introduced or used was recorded. 


\subsection{Categorization of degree of specialization and explicitation shifts}

The analysis conducted included two interrelated steps. The first one involved the identification of shifts in the degree of specialization. This first step was necessary as explicitation and implicitation shifts overall are a type of shift in which the translation displays a higher or lower degree of specialization, for example when an LG term is substituted in the translation by a lay term or vice versa. The use of LG terms in specialized texts contributes to their degree of specialization and terminological density. It is understood to be an indication of the degree of specialization of a text (Cabré 1999: 89). In this context and as previously explained, the translation of any medical concept can include shift in implicitness or explicitness when a reformulation is added or omitted in the translation. For example, the following translation, Myalgia > 'Mialgia (dolor muscular)' [Myalgia (muscle aches)], shows a more explicit formulation with the LG term accompanied by a reformulation or layterm. This simultaneously contributes to lowering slightly the degree of specialization by combining a specialized term with a lay one. Nevertheless, in the corpus it is also possible to identify shifts in the degree of specialization that do not involve explicitation o implicitation. For example, in the following instance from the corpus: air hunger (feeling that you cannot get enough air) > 'Disnea (sensación de que uno no recibe suficiente aire)', the layterm air hunger followed by a reformulation that is translated by using the LG term in Spanish, 'disnea', followed by a literal rendition of the intralingual explicitation found in the source text. This represents a clear case of degree of specialization shift that does not involve an explicitation-implicitation shift in the translation.

These shifts in the degree of specialization can include any permutation between LG terms and lay terminological variants. There were three possible categories for degree of specialization shifts: 1. Same degree of specialization, 2. Lower to higher, 3. Higher to lower. Figure 1 shows the possible shifts within each category. 
Table 1. Categorization of possible shifts in the degree of specialization

\begin{tabular}{|l|l|l|l|}
\hline \multicolumn{1}{|c|}{ Shift } & \multicolumn{3}{c|}{ Degree of Specialization } \\
\hline & $\begin{array}{l}\text { Same } \\
1 . \text { S- } \varnothing\end{array}$ & $\begin{array}{l}\text { Lower to Higher } \\
\text { 2. L }>\text { H }\end{array}$ & $\begin{array}{l}\text { Higher to Lower } \\
\text { 3. H }>\text { L }\end{array}$ \\
\hline $\begin{array}{l}\text { No Shift- } \\
\text { Direct translation }\end{array}$ & 1. S- $\varnothing$ & & \\
\hline Substitution & & 2a.L $>$ H-Subst & 3a. H $>$ L-Subst \\
\hline Explicitation & & 2b.L $>$ H-Expl & 3b. H $>$ L-Expl \\
\hline Implicitation & & 2c.L $>$ H-Impl & 3c. H $>$ L-Impl \\
\hline Doublet Inversion & & 2d.L $>$ H-Doublet.Inv & 3d.H $>$ L-Doublet.Inv \\
\hline
\end{tabular}

The first category, 1. S- $\varnothing$ involves no change in the degree of specialization, that is, the LG term stays the same in the translation. This involves a direct or literal translation of the source text, maintaining the same patterns of lexical use as in the source text, both in the single use of the LG term or the combined used of an LG term with its reformulation or intralingual lexical explicitation.

1. Degree of specialization shift: $\varnothing$ same

Hypoglycemia > 'Hipoglucemia'

Hypoglycemia, or low blood sugar > 'Hipoglucemia, o azúcar bajo en la sangre'

Categories $2(\mathrm{~L}>\mathrm{H})$ and $3(\mathrm{H}>\mathrm{L})$ involve shifts from lower to higher degree of specialization or vice versa. They are subdivided into four possible subcategories that involve a shift by means of using (a) substitution, (b) explicitation, (c) implicitation, or (d) doublet inversion.

Substitution ( $2 \mathrm{a}$ and $3 \mathrm{a}$ ), involves for example a shift by means of substituting a lay term, such as shortness of breath, for the corresponding LG term in the Spanish translation, 'disnea'. This is a case of increasing the degree of specialization, 2a.L>H-Subs, but this can also happen in the opposite direction, with the LG term substituted entirely by a lay term, 3a.L >H-Subs.

2.a. L>H-Subs. Degree of Specialization/Low to High/ Substitution

....if you experience shortness of breath > '... si tiene disnea'. 
...has trouble breathing (shortness of breath) > ... 'tiene dificultad para respirar (disnea)'.

Explicitation (subcategories $2 \mathrm{~b}$ and $3 \mathrm{~b}$ ) involve adding a doublet, either a LG term to a lay term or vice versa. It can involve adding a lay term or reformulation to an existing LG term in the source text, lowering the degree of specialization, 3b. H>L-Expl. This is considered as one of the explicitation categories, as from one term the translation rendering includes two. It is also possible that the translation can involve a LG term added to a lay term, 2b.L $>\mathrm{H}$-Expl. This is also considered as one of the explicitation categories.

2.b. L>H-Expl. Degree of Specialization/Lower to Higher /Explicitation Shortness of breath > 'disnea (dificultad para respirar)' [dyspnea (difficulty breathing)]

Implicitation (subcategories 2.c. and 3.c.) involve implicitation shifts by eliminating-deleting one part of a doublet, going from LG term plus reformulation in any order to just one. This is a less explicit formulation and therefore identified as implicitation in this study. Depending on which part is deleted the degree of specialization is increased, 2c.L>H-Impl, or lowered 3c.H>L-Impl.

2.c. L $>$ H-Impl Degree of Specialization/Low to High/ Implicitation

- Low blood sugar (hypoglycemia) > 'Hipoglucemia'

3.c. $\mathrm{H}>\mathrm{L}-\mathrm{Impl}$.

- Myalgia > 'Mialgia (dolor muscular)'

Double inversion (subcategories 2.d. and 3.d.) involves a minimal shift in the degree of specialization within the low to high continuum. Here the LG term and its reformulation are reversed, presenting the LG term first, rather than second, or the other way around. This involves no explicitation shift, but rather an inversion as it might be perceived that the LG term is more transparent to target text users to be presented first.

2.d.Degree of Specialization/Lower to Higher/ Doublet Inversion.

- Low blood sugar (hypoglycemia)' > Hipoglucemia (nivel bajo de azúcar en la sangre)' 
After this categorization of the shifts in the degree of specialization, categories 2.b, 2.c., 3.b and 3.c would be representative of more or less explicit formulations, and therefore indicative of the tendencies under study here.

Table 2. Categorization of explicitation and implicitation shifts

\begin{tabular}{|c|c|c|c|}
\hline \multicolumn{2}{|c|}{ Explicitation/Implicitation Shifts } & \multicolumn{2}{|c|}{ Target Text Shifts } \\
\hline Source Texts & $\begin{array}{l}\text { Intralingual Explicitation } \\
\text { ( } 2 \text { or more terms / } \\
\text { expressions to render a } \\
\text { concept) }\end{array}$ & $\begin{array}{l}\varnothing \text { Literal } \\
\text { translation }\end{array}$ & Implicitation \\
\hline & $\begin{array}{l}\text { No intralingual } \\
\text { explicitation } \\
\text { (1 term to render a concept) }\end{array}$ & $\begin{array}{l}\emptyset \text { Same. Literal } \\
\text { translation }\end{array}$ & Explicitation \\
\hline
\end{tabular}

The analysis of the data yielded four possible types of explicitation/implicitation shifts. The source text can display either a single medical term variant, or can use two or more. Explicitation shifts will be observed if the translation displays more than one terminological variant or a reformulation, while all instances of source texts that display intralinguistic explicitation (HillMadsen 2015) can be rendered as a single terminological or reformulation variant.

The first category would be observed if there is a literal translation of a doublet such as:

(1) Shortness of breath (dyspnea) > 'Falta de aire (disnea)'

(2) A lower-than-normal blood glucose level (hypoglycemia) > 'Un nivel de glucosa en la sangre inferior a lo normal (hipoglucemia)'

Meanwhile, an implicitation shift would emerge if any of the two parts would be deleted.

(1) Shortness of breath (dyspnea) > 'Disnea'

This case is not limited to instances of two terms or lexical units in which one is omitted, since some examples in the corpus include up to three reformulations (e.g. "Dyspnea is the feeling of difficult or uncomfortable breathing or of not getting enough air" (EN)- "La disnea es la sensación de dificultad o incomodidad para respirar, o de no conseguir suficiente aire". 
The omission of any of these three lexical units could be considered as an implicitation shift.

On the other hand, any instance of a single LG term or lay variant can be more explicit in the translation if it is accompanied by a second variant or reformulation.

(1) Low blood sugar > 'un nivel bajo de azúcar en la sangre (hipoglucemia)' [a low level of sugar in the blood (hypoglycemia)]

(2) Myalgia > 'mialgia (dolor muscular)' [myalgia (muscle pain)].

This study thus clearly defines what is explicit and implicit (De Metsenaere $\&$ Vandepitte 2017: 387), namely LG reformulation or determinologization (or the omission thereof) in the translation. As previously mentioned, given the different level of specialization attributed to many LG terms between Spanish and English, it should be expected that in the English to Spanish direction the reformulation of the LG term could be sometimes deleted in the translation process (Montalt \& González Davies 2005; Campos Andrés 2013). Therefore, the decision to insert or delete a doublet or the use/absence of a determinologization strategy with a specialized term in a semi-specialized text is considered indicative of explicitness or implicitness in translation.

\section{Results}

The results of the parallel corpus analysis point to 316 instances in which the selected LG terms were translated in the corpus from English into Spanish. These cases identified might seem in principle a small volume considering the corpus size, but it should be remembered that only the selected medical terms in the previous study were used, and only the first instance per webpage was selected.

\subsection{Results: Shifts in the degree of specialization or technicality}

Table 3 shows the results of the contrastive analysis of degree of specialization or technicality. In $80.69 \%$ of the instances (255 of the total 316) the translation did not present a shift in the degree of specialization, that is, the translation showed a direct or literal rendering of the source text, as compared to $19.31 \%$ of shifts (61 of 316 instances). Within this, in 19\% of 
instances of medical concepts under study there was a shift from lower to higher degree of specialization, while only $0.31 \%$ of cases involved lowering the degree of specialization. This means that translated texts showed a marked tendency to keep the same degree of specialization as the source text by means of replication of source language structures. In those cases where a shift occurs, the most frequent one is to increase the level of specialization by adding a doublet, that is, translating a lay term in English by adding also the LG term, that is explicitation $(52.46 \%$ of the shifts, $10.12 \%$ of the total instances). The next most frequent one involved going from lower to higher degree of specialization by substituting a lay term for a LG term $(44.26 \%$ of shifts, $8.54 \%$ of total instances). Last but not least, another shift that does not involve explicitation or implicitation but that is argued here as a shift, a doublet inversion from higher to lower degree of specialization, is present in $0.31 \%$ of cases. This shift often involves an LG term followed by a reformulation or lay term that is reversed in the translated text.

Table 3. Results. Degree of specialization shifts

\begin{tabular}{|c|c|c|}
\hline \multicolumn{3}{|c|}{$\begin{array}{l}\text { Degree of Specialization } \\
\text { Total instances } N=316\end{array}$} \\
\hline No Shift & \multicolumn{2}{|c|}{ Shift } \\
\hline \multirow[t]{5}{*}{$\begin{array}{l}80.69 \% \\
\mathrm{~N}=255\end{array}$} & $\begin{array}{l}\text { Low to High } \mathrm{L}>\mathrm{H}(19 \%) \\
\mathrm{N}=60\end{array}$ & $\begin{array}{l}\text { High to Low } \mathrm{H}>\mathrm{L}(0.31 \%) \\
\mathrm{N}=1\end{array}$ \\
\hline & $\begin{array}{l}\text { 2a.L>H-Subst } \\
44.26 \% \text { ( } 8.54 \text { of total instances) } \\
\mathrm{N}=27\end{array}$ & $\begin{array}{l}\text { 3.a. H>L-Subst } \\
0 \% \\
\mathrm{~N}=0\end{array}$ \\
\hline & $\begin{array}{l}\text { 2b.L }>\mathrm{H}-\mathrm{Expl} \\
52.46 \%(10.12 \% \text { of total } \\
\text { instances) } \\
\mathrm{N}=32\end{array}$ & $\begin{array}{l}3 \mathrm{~b} . \mathrm{H}>\mathrm{L}-\mathrm{Expl} \\
1.64 \%(0.31 \text { of total instances }) \\
\mathrm{N}: 1\end{array}$ \\
\hline & $\begin{array}{l}\text { 2c.L>H-Impl } \\
0 \% \\
\mathrm{~N}=0\end{array}$ & $\begin{array}{l}\text { 3c. H>L-Impl } \\
0 \% \\
\mathrm{~N}=0\end{array}$ \\
\hline & $\begin{array}{l}\text { 2d.L>H-Doublet.Inv } \\
1.64 \% \\
\mathrm{~N}=1\end{array}$ & $\begin{array}{l}3 \mathrm{~d} . \mathrm{H}>\mathrm{L}-\text { Doublet.Inv } \\
0 \% \\
\mathrm{~N}=0\end{array}$ \\
\hline
\end{tabular}


In sum, if the results are compiled 19\% of instances of medical concepts in this study showed a lower to higher degree of specialization shift. The reverse option, a shift from higher to lower degree of specialization only appeared in $0.31 \%$ of cases. It should be noted that explicitation shifts in terms of shifts in the degree of specialization are the most common, and that implicitation is not found in the corpus under study. These results therefore also confirm $\mathrm{H} 2$, as explicitation found in translated texts is due to a combination of ST structure replication, as well to translation-inherent explicitation.

\subsection{Results: Analysis of implicitation- explicitation shifts}

In the dataset for this study (316 LG terms), 153 instances in the dataset would allow for implicitation shifts, as the ST includes a doublet or triplet, that is, the medical concept is rendered in the ST through multiple terms. This could be considered cases of intralingual explicitation (Hill-Madsen 2015). Meanwhile, 165 cases would allow for explicitation shifts as the medical concept is rendered through a monolexical terminological unit.

The results show that when explicitation is possible, a shift is identified in $20.6 \%(34 / 165)$ of possible cases, while there are no implicitation shifts $(0 / 147)(p=<0.0001)^{2}$. Explicitation shifts are therefore quite more prevalent than implicitation ones in the dataset. This higher tendency for explicitation can be even found in instances in which a doublet in the ST has been rendered with three terms or lexical units, such as the following:

(1) This condition is called shortness of breath. The medical term for this is dyspnea. > 'Esta afección se denomina falta de aliento o dificultad para respirar. El término médico para esto es disnea' [This condition is known as shortness of breath or difficulty breathing. The medical term is dyspnea]

2. Two-tailed Fisher's exact test. 
Table 4. Results of explicitation and implicitation shift analysis in parallel corpus

\begin{tabular}{|l|l|l|l|}
\hline \multicolumn{2}{|c|}{ Explicitation/Implicitation Shifts } & \multicolumn{2}{c|}{ Target Text Shifts } \\
\hline \multirow{3}{*}{ Source Texts } & Intralingual & $\emptyset$ Literal & Implicitation \\
& Explicitation & translation & $\mathrm{N}: 147$ \\
\hline & \multirow{3}{*}{ No intralingual } & $\emptyset$ Same. Literal & Explicitation \\
& explicitation & translation & $\mathrm{N}: 34$ \\
& & $\mathrm{~N}: 131$ & $20.6 \%$ \\
\hline
\end{tabular}

In this case the lay term, shortness of breath, followed by an explanation that indicates that the medical term for this is dyspnea, is translated by using two layterms in Spanish, 'falta de aliento' and 'dificultad para respirar', followed also by the medical term dyspnea. It should be mentioned that in the corpus there were instances of deletion, primarily in pronunciation information for English speaking patients that was deleted in the translation. Spanish target readers can easily read any LG term and therefore that aid for source language readers is not necessary and deleted "dyspnea (DISP-nee-uh): Difficult, painful breathing or shortness of breath" > 'disnea: Respiración difícil, dolorosa o deficiencia respiratoria.

\section{Discussion}

In the previous comparable corpus study (Jiménez-Crespo \& Tercedor 2017), LG terms in translations were accompanied by a reformulation in $40.6 \%$ of cases, while it was $21.23 \%$ for those found in the non-translational corpus. This means that translations contained overall higher rates of explicitation of LG terms, and whether it was the direct result, or not, of the translational process could not be identified with that comparable corpus. These results show that when the concepts under study appear in source or target texts, $10.44 \%$ of overall cases can be attributed to translation-specific or translation-inherent explicitation. These results, although not fully comparable, do not match the difference between the translational and non-translational ratios found in the previous study. The remaining cases can therefore be attributed to cross-linguistic effects (Kruger \& Van Rooy 2016). This can therefore be indicative that (1) the translation process leave unmistakable 
traces of explicitation in translation products, (2) implicitation shifts do not appear in translation products under study, even when it could be possible, (3) higher levels of explicitation in translated texts when compared to non-translated ones are due to cross-linguistic effects, that is, translators simply replicate existing source text structures regardless of possible language specific differences in the genre under examination and (4) combining comparable and parallel corpora can provide a clearer and richer picture of general tendencies and potential causes.

The results therefore offer support for $\mathrm{Hl}$, as translated texts show higher ratios of explicitation than implicitation. In addition, this preference appears in a specific case in which implicitation might be suitable or might be a preferred option in the target language.

RQ 2 indicated that if $\mathrm{H} 2$ would be confirmed, it would offer support for the interference or cross-linguistic effects hypothesis, as well as for the risk-aversion hypothesis. It is clear that most cases of explicitation are due to cross-linguistic effects, thus offering support for this proposed hypothesis. The translations do show traces of the existing contrastive differences between both languages, as LG terms are less commonly used in Spanish than in English. As far as the risk aversion hypothesis, the picture that emerges is less clear and needs to be explored in future studies. It is clear that explicitation is preferred to implicitation, and translations are more explicit than non-translations. When it is possible to explicitate, $20.6 \%$ of cases include explicitation, with no cases of implicitation. Nevertheless, this study has also shown that explicitation strategies go hand in hand with shifts in the degree of specialization, such as changing a layterm in the source text for a LG term (8.54\%) (e.g. 'muscle pain' translated as 'myalgia' in Spanish). This raises the question of how explicitation interacts with other lexical shifts in terms of risk avoidance or making the text more clear or easy to understand. Approximately half the cases involve explicitation shifts by adding a LG term to a lay lexical unit, a strategy that might lead to increase the ease of comprehension, while the other half solely involve substituting a lay term for an LG term. It is quite possible that the explicitation ratios here are due to risk avoidance, but it is not fully clear then, as well as a potential question for future studies, whether risk avoidance strategies can be confirmed using only one possible strategy out of many possible factors. What 
is clear is that studying lexical explicitation with other lexical shifts might provide a broader and more complete picture.

\section{Final remarks}

The motivation for this study was to offer a clearer insight into the differences in the frequency of use of LG terms and explicitation ratios between translated and non-translated texts as described in a previous study (JiménezCrespo \& Tercedor 2017). This paper has shown that the observed differences can primarily be attributed to language and genre specific differences in the language pair involved, that is, they can be attributed to direct transferring of the source text structures, with a percentage of what can be called translation-inherent explicitation (20.6\% of possible cases), that is, shifts seem to emerge due to the specific communicative nature of the translation process itself. This general tendency is further supported by the fact that there were no cases of implicitation, even when this strategy was possible and/or appropriate. These results thus add to the body of literature that confirms explicitation as a general tendency in translation. They also offer support for the cross-linguistic effect (Kruger \& Van Rooy 2016) as a possible causality of higher explicitation rates in translations than in similar non-translated texts, as translations primarily replicate source text structures in English source texts. The study offers a more lukewarm support for the risk aversion hypothesis, with one fifth of possible cases using explicitation. This study has shown that other types of lexical shifts might interact with these explicitation shifts, the objective of future studies. What is clear is that the combination of the parallel and comparable corpus methodologies has offered strong support for the existence of translation-inherent explicitation, and a combination of both methodologies seems suitable for the study of these phenomena. 


\section{References}

AlarCón, Esperanza; Clara Inés López-Rodríguez \& Maribel Tercedor. (2016) "Variation dénominative et familiarité en tant que source d'incertitude en traduction médicale." Meta 61:1, pp. 117-145.

Askehave, Inger \& Karen K. Zethsen. (2000) "Medical Texts Made simple Dream or Reality?" Hermes: Journal of Linguistics 23, pp. 63-74.

BAKER, Mona. (1995) "Corpora in translation studies: An overview and some suggestions for future research.” Target 7:2, pp. 223-243.

BAKER, Mona. (1996) "Corpus-based Translation Studies: The Challenges that Lie Ahead." In: Somers, Harold (ed.) (1996) Terminology, LSP and Translation: Studies in Language Engineering in Honour of Juan C. Sager. AmsterdamPhiladelphia: John Benjamins, pp. 175-186.

BECHER, Viktor. (2010) "Abandoning the notion of "translation-inherent" explicitation. Against a dogma of translation studies." Across Languages and Cultures 11:1, pp. 1-28.

BECHER, Viktor. (2011) Explicitation and Implicitation in Translation. A Corpus-based Study of English-German and German-English Translations of Business Texts. PhD thesis. Hamburg: Universität Hamburg, Fakultät für Geisteswissenschaften.

BISIADA, Mario. (2017) "Universals of editing and translation." In: HansenSchirra, Silvia; Oliver Czulo \& Sascha Hofmann (eds.) (2017) Empirical modelling of translation and interpreting. Berlin: Language Science Press, pp. 241-275. DOI:10.5281/zenodo.1090972

Blum-KulKa, Shoshana. (1986) "Shifts of Cohesion and Coherence in Translation." In: House, Julianne \& Shoshana Blum-Kulka (eds.) (1986) Interlingual and Intercultural Communication: Discourse and Cognition in Translation and Second Language Acquisition Studies. Tübingen: Gunter Narr, pp. 17-35.

CAMPOS ANDRÉs, Olga. (2013) "Procedimientos de desterminologización: traducción y redacción de guías para pacientes". Panace@ 14,pp. 48-52.

Chesterman, Andrew. (2004) "Beyond the Particular." In: Mauranen, Anna \& Pekka Kujamäki (eds.) (2004) Translation Universals. Do they Exist? Amsterdam-Philadelphia: Benjamins, pp. 33-49.

De Metsenarere, Hinde \& Sonia Vandepitte. (2017) "Towards a Theoretical Foundation for Explicitation and Implicitation." Trans-Komm 10:3, pp. 385-419. 
De Sutter, Gert \& Patrick Goethals; Torsten Leuschner \& Sonia Vandepitte. (2012) "Towards methodologically more rigorous corpus-based translation studies." Across Languages and Cultures 13:2, pp. 137-143.

De SutTer, Gert \& Marie-Aude Lefer. (2020) "On the need for a new research agenda for corpus-based translation studies: a multi-methodological, multifactorial and interdisciplinary approach." Perspectives 28:1, pp. 1-23

DENTURK, Kathelenje. (2012) "Explicitation vs. implicitation: a bidirectional corpus-based analysis of causal connectives in French and Dutch translations." Across Languages and Cultures 13, pp. 211-227.

Englund-Dimitrova, Birgitta. (2005) Expertise and Explicitation in the Translation. Amsterdam-Philadelphia: John Benjamins.

ERFIENI, Ni Made Diana. (2017) "Explicitation And Implicitation In The Literature Translation For Children." LITERA: Jurnal Litera Bahasa Dan Sastra 3:1, pp. 31-39.

EWA, Gumul. (2006) "Explicitation in Simultaneous Interpreting: A Strategy or a By-Product of Language Mediation." Across Languages and Cultures 7:2, pp. 171-190.

EzPEleta, Pilar. (2012) "An Example of Genre Shift in the Medicinal Product Information Genre System." Linguistica Antverpiensia, New Series Themes in Translation Studies 11, pp. 139-159

FABER, Dorrit \& Mette Hjort-Pedersen. (2013) "Expectancy and Professional Norms in Legal Translation: A Study of Explicitation and Implicitation Preferences." Fachsprache 2013 1-2, pp. 43-63.

GutiÉRREZ RodiLla, Bertha. (2014) "El lenguaje de la medicina en español: cómo hemos llegado hasta aquí y qué futuro nos espera”. Panace@ 15, pp. 86-94. HALVERSON, Sandra. (2016) "Cognitive Translation Studies and the merging of empirical paradigms." Translation Spaces 4, pp. 310-340.

HANSEN-SCHIRRA, Silvia; Stella Neumann \& Erich Steiner. (2007) "Cohesive Explicitness and Explicitation in an English-German Translation Corpus." Languages in Contrast 7:2, pp. 241-266.

Hill-Madsen, Aage. (2015) "Lexical Strategies in Intralingual Translation between Registers." Hermes - Journal of Language and Communication in Business 54, pp. 85-105.

HJORT, Pedersen; Mette Faber \& Dorrit Faber. (2010) "Explicitation and Implicitation in Legal Translation. A Process Study of Trainee Translators." Meta: Translators Journal 55:2, pp. 237-250. 
JiMÉNEZ-CRESPO, Miguel A. (2011) "The future of general tendencies in translation: Explicitation in web localization." Target 23:1, pp. 3-25.

JimÉnEZ-CRESPO, Miguel A. (2012) "Loss or lost in localization: A corpus-based study of original and localized non-profit websites." JoStrans: the Journal of Specialised Translation 17, pp. 136-165.

JIMÉNEZ-CRESPO, Miguel A. (2016) "Testing explicitation in translation: triangulating corpus and experimental studies." Across Languages and Cultures 16:1, pp. 257-283.

JiMÉNEZ-CRESPO, Miguel A. \& Maribel Tercedor. (2017) "Lexical Variation, Register and Explicitation in Medical Translation: A Comparable Corpus Study of Medical Terminology in US Websites Translated into Spanish." TIS: Translation and Interpreting Studies 12: 3, pp. 405-426.

Klaudy, Kinga. (1998) “Explicitation.” In: Baker, Mona (ed.) (1998). Encyclopedia of Translation Studies. London: Routledge, pp. 80-85.

KLAuDY, Kinga. (2001) "The asymmetry hypothesis: Testing the asymmetric relationship between explicitations and implicitations." Paper presented at the Third EST Congress, Claims, changes and challenges in translation studies, Copenhagen.

KLAUDY, Kinga \& Kristina Károly. (2005) "Implicitation in translation: Empirical evidence for operational asymmetry in translation." Across Languages and Cultures 6:1, pp. 13-28.

KRÜGER, Ralph. (2014) Exploring the interface between scientific and technical translation and cognitive linguistics: The case of explicitation and implicitation. University of Salford. Unpublished PhD thesis.

KRÜGER, Ralph. (2015) The interface between scientific and technical translation studies and cognitive linguistics: with a special emphasis on explicitation and implicitation as indicators of translations text-context interaction. Berlin: Frank Timme.

KRÜGER, Ralph. (2016) "The textual degree of technicality as a potential factor influencing the occurrence of explicitation in scientific and technical translation." Jostrans: The Journal of Specialized Translation 26, pp. 96-115.

Kruger, Heide \& Bertus Van Rooy. (2016) "Syntactic and pragmatic transfer effects in reported-speech constructions in three contact varieties of English influenced by Afrikaans." Language Sciences 56, pp. 118-131. https://doi. org/10.1016/j.langsci.2016.04.003 
KrUgER, Heide. (2018) "That Again: A Multivariate Analysis of the Factors Conditioning Syntactic Explicitness in Translated English." Across Languages and Cultures 20:1, pp. 1-33. https://doi.org/10.1556/084.001.

KRUGER, Heide \& Gert De Sutter. (2018) "Reconceptualising that-omission in translated and non-translated English using the MuPDAR approach." Translation, Cognition and Behaviour 1:2, pp. 251-290.

KRUGER, Heide \& Gert De Sutter. (2018) "Alternations in contact and non-contact varieties: Reconceptualising that-omission in translated and non-translated English using the MuPDAR." Translation, Cognition \& Behavior 1:2, pp. 251-290.

Laviosa, Sara. (2002) Corpus-Based Translation Studies. Theory, Findings, Applications. Amsterdam-New York: Rodopi.

MAKKOS, Aniko \& Edina Robin. (2014) "Explicitation and Implicitation in Back-translation." Current Trends in Translation Teaching and Learning 5, pp. 151-182.

MAREVA, Amelia. (2017) Lexical Explicitation and Implicitation in Experts' and Students' Literary Translations: An Empirical Contrastive Study. Working Paper. New Bulgarian University Scholar Electronic Repository, Sofia. Electronic version: <https://scinapse.io/papers/2778145166>

MEYER, Ingrid \& Kristen Mackintosh. (2000) "When terms move into our everyday lives: an overview of determinologization." Terminology 6:1, pp. 111-138.

NisBETH Jensen; Matilde Zethsen \& Karen Zethsen. (2012) "Patient Information Leaflets: Trained Translators and Pharmacists-cum-translators - a comparison." Linguistica Antverpiensia New Series. Themes in Translation Studies 11, pp. 31-49.

Montalt, Vicent \& María González Davies. (2007) Medical Translation Step by Step. Translation Practices Explained. Manchester: St. Jerome Publishing.

MONTALT, Vincent \& Mark Shuttleworth. (2012) "Translation and knowledge mediation in medical and health settings." Linguistica Antverpiensia New Series - Themes in Translation Studies 11, pp. 95-112.

Montalt, Vicent; Karen Zethsen \& Wioleta Karwacka. (2018) "Medical Translation in the $21^{\text {st }}$ Century: Challenges and Trends." MonTI 10, pp. 27-42.

MuÑoz-Miquel, Ana. (2012) "From the Original Article to the Summary for Patients: Reformulation Procedures in Intralingual Translation." Linguistica Antverpiensia, New Series Themes in Translation Studies 11, pp. 187-206. 
MURTISARI, Elisabeth T. (2013) "A relevance-based framework for explicitation and implicitation: An alternative typology." Trans-kom 6:2, pp. 315-344.

MURTISARI, Elisabeth T. (2016) "Explicitation in Translation Studies: The journey of an elusive concept." Translation \& Interpreting 8:2, pp. 64-81.

OAKes, Michael \& Meng Ji. (2012) Quantitative Methods in Corpus-Based Translation Studies: A practical guide to descriptive translation research. New York-London: Routledge.

OlOhan, Maeve. (2004) Introducing Corpora in Translation Studies. London: Routledge.

Olohan, Maeve \& Mona Baker. (2000) "Reporting that in translated English: Evidence for subconscious processes of explicitation?" Across Languages and Cultures 1:2, pp. 141-158.

ØVERVERÅs, Linn. (1998) "In search of the third code: An investigation of norms in literary translation." Meta 43:4, pp. 557-570.

Perego, Elisa. (2003) "Evidence of Explicitation in Subtitling: Towards a Categorisation." Across Languages and Cultures 4:1, pp. 63-88.

PUURTINEN, Tina. (2004) "Explicitation of clausal relations: A corpus-based analysis of clause. Connectives in translated and non-translated Finnish children's literature." In: Mauranen, Anna \& Pekka Kujamäki (eds.) (2004) Translation universals: Do they exist? Amsterdam-Philadelphia: John Benjamins, pp. 165-76.

PyM, Anthony. (2005) "Explaining explicitation." In: Karoly, Kristina \& Agota Foris (eds.) (2005) New Trends in Translation studies: In Honour of Kinga Klaudy. Budapest. Akademiai Kiado, pp. 29-34.

PyM, Anthony. (2015) "Translating as Risk Management." Journal of Pragmatics 85 , pp. 67-80.

TANG, Fang. (2018) Explicitation in Consecutive Interpreting. AmsterdamPhiladelphia: John Benjamins.

TAO, Yuan \& Zanhao Jiang. (2017) "Translation universals of kak structures: a corpus-based approach”. Russian Linguist Linguistics 41:1, pp. 61-78.

TERCEDOR, Maribel \& Clara Inés López Rodríguez. (2012) "Access to health in an intercultural setting: the role of corpora and images in grasping term variation." Linguistica Antverpiensia, New Series-Themes in Translation Studies 11, pp. 247-268. 
Tercedor, María Isabel; Clara Inés López Rodríguez \& Juan A. Prieto Velasco. (2014) "También los pacientes hacen terminología: retos del proyecto VariMed”.Panace@ 15,pp. 95-102.

VAn BeVEREN, Amelie; Gert De Sutter \& Thimoty Colleman. (2018) "Questioning explicitation in translation studies: a multifactorial corpus investigation of the om-alternation in translated and original Dutch." UCCTS 2018 Conference, University of Louvain, 12-14 Sept. 2018.

VAN DAM, Helle; Matilde Brogger \& Karen Zethsen. (2018) Moving Boundaries in Translation Studies. New York-London: Routledge.

VinAY, Jean Paul \& Jean Dalbernet. (1958) Stylistique comparée du français et de l'anglais. Paris: Didier.

ZethSEN, Karen K. (2004) "Latin -Based Terms: True or False Friends?" Target 16:1, pp. 125-142.

\section{BIONOTE / BIONOTA}

Miguel A. JimÉNEZ-CRESPO holds a PhD in Translation and Interpreting Studies from the University of Granada, Spain. He is a Professor in the Department of Spanish and Portuguese, Rutgers University, and he directs the MA program and the undergraduate certificate in Spanish - English Translation and Interpreting. He is the author of Crowdsourcing and Online Collaborative Translations: Expanding the Limits of Translation Studies (translated into Korean) published by John Benjamins in 2017, as well as Translation and Web Localization published by Routledge in 2013.

MARIBEL TERCEDOR SANCHEZ is full professor at the Department of Translation and Interpreting of the University of Granada, where she teaches Multimedia and Scientific and Technical translation. She has directed the VariMed project on medical terminology (http://varimed.ugr.es) and codirected with Clara I. López Rodríguez the CombiMed project on lexical combinations in Medicine. Her main research interests are in the fields of lexical and cognitive aspects of scientific and technical translation, terminology (variation and phraseology) and accessibility in translation. She is the author of a number of academic papers in these fields. 
Miguel A. JimÉnEZ-CRESPO es doctor en Traducción e Interpretación por la Universidad de Granada. Es catedrático en el Departamento de Español y Portugués en la Universidad de Rutgers, EEUU, donde dirige el programa de traducción e interpretación. Es el autor del libro Crowdsourcing and Online Collaborative Translations: Expanding the Limits of Translation Studies, publicado en 2017 por John Benjamins y de Translation and Web Localization (tradudico al coreano) publicado en 2013 por Routledge.

MARIBEL TERCEDOR SÁNCHEZ es catedrática en el Departamento de Traducción e Interpretación de la Universidad de Granada. Imparte docencia de Traducción Multimedia y Traducción Científica y Técnica. Ha dirigido el proyecto VariMed sobre terminología médica y codirigido, con la Dra. López Rodríguez, el proyecto CombiMed sobre combinaciones léxicas en Medicina. Sus intereses en investigación se centran en los ámbitos del léxico y cognición en la traducción de textos científicos y técnicos, terminología (variación y fraseología) y accesibilidad en traducción, ámbitos en los que ha publicado sus resultados de investigación. 